\title{
CLINICAL PROFILE OF FEMALE SUICIDE ATTEMPTERS -A HOSPITAL BASED STUDY
}

\author{
Fiaz Ahmed Sattar', Swapna Bondade², Kiran Kumar K3
}

1 Professor and HOD, Department of Psychiatry, Vydehi Institute of Medical Sciences and Research Center, Bangalore. ${ }^{2}$ Associate Professor, Department of Psychiatry, The Oxford Medical College, Hospital and Research Center, Bangalore. ${ }^{3}$ Assistant Professor, Department of Psychiatry, Vydehi Institute of Medical Sciences and Research Center, Bangalore.

\begin{abstract}
BACKGROUND: "Gender Paradox" is a known phenomenon in the field of suicidology and over the past century, there has been a dramatic change in the gender role of females in the entire bio psychosocial domain which is affecting their mental health. The present study tries to analyze these determinantal factors contributing to female suicide attempts.
\end{abstract}

AIM: To study the clinical profile of female suicide attempters.

METHODOLOGY: Fifty seven subjects fulfilling the inclusion and exclusion criteria were recruited in the study. The sociodemographic details were recorded in the semi-structured proforma. Detailed assessment of Psychiatric morbidity and attempted suicide was done by clinical interview and validated by M.I.N.I.-Plus and Beck Suicide Intent Scale. Statistical analysis was done with the help of SPSS version 16.

RESULTS: In this study, we had 57 cases most of them belonged to the age group of 11-20 yrs (56\%), were married (51\%), and were from urban background (75\%). Poisoning (44\%) was the most common mode of attempt followed by drug overdose (32\%). The attempt was of low lethality in $72 \%$ and $53 \%$ of the cases had high intentionality. Marital discords followed by interpersonal conflicts were the common stressors. In this study $75 \%$ of the cases were diagnosed to be having Adjustment Disorder followed by Depressive disorder in $16 \%$.

CONCLUSION: Marital discord and interpersonal conflicts were the major stressors in the female attempters and majority of the patients had a psychiatric diagnosis so early detection and intervention will reduce the morbidity and mortality.

KEYWORDS: Female; Suicide; Attempters.

HOW TO CITE THIS ARTICLE: Fiaz Ahmed Sattar, Swapna Bondade, Kiran Kumar. K. "Clinical Profile of Female Suicide Attempters -A Hospital Based Study". Journal of Evolution of Medical and Dental Sciences 2015; Vol. 4, Issue 92, November 16; Page: 15741-15745, DOI: $10.14260 /$ jemds/2015/2273.

INTRODUCTION: Suicide is a deeply personal and an individual act but the behaviour is determined by a complex interaction between biological, psychological, social and situational factors. Every year, almost one million people die from suicide; a "global" mortality rate of 16 per 100,000, or one death every 40 seconds.(1) In India, the number of suicides in the country during the decade (2003-2013) has recorded an increase of $21.6 \%(1,34,799$ in 2013 from $1,10,851$ in 2003) according to National Crime Records Bureau (NCRB) data.(2) It is estimated that one in 60 persons are affected by suicide in this country. It includes those who have attempted suicide and those who are affected by suicide of a close family and friend.(3)

Suicide attempts occur 8-10 times more frequently than completed suicide.(4) Attempted suicide does not represent a diagnostic pattern but is usually a behavior determined by both the person himself and the social environment in which one functions. Thus, attempted suicide is a common clinical problem with complex origins.

Financial or Other, Competing Interest: None.

Submission 21-10-2015, Peer Review 23-10-2015,

Acceptance 04-11-2015, Published 14-11-2015.

Corresponding Author:

Dr. Kiran Kumar K,

Assiatant Professor, Room No. 112, Department of Psychiatry,

Vydehi Institute of Medical SSciences and Research Center,

EPIP Area, Whitefield, Bangalore-560066.

E-mail: drkiran.psychiatry@gmail.com

DOI:10.14260/jemds/2015/2273.
The magnitude of this problem, its relevance in terms of public health and the need for developing effective prevention strategies to prevent people committing this act, makes heavy demands on psychiatric services. (3)

Although the experience of suicidal behavior is unique and individual in nature, a number of bio-psychosocial and cultural factors have been found to influence the risk of suicide in women. Over the past century, there have been dramatic changes in their role and it has broadened to include work, education and family. Suicide research consistently demonstrates that women have higher rates of suicidal behavior, i.e. ideation, planning and suicide attempts compared to men; however men are more likely to die by suicide.

This is referred to as the "Gender Paradox in Suicide" ${ }^{(5,6,7)}$ The factors influencing the attempt are different in different genders. These factors interact with a confluence of social determinants, for example intimate partner violence, culture, geographic location, and discrimination, to influence patterns of women's suicidality. The role of female in today's world is multidimensional and given the fact that risk of suicidal attempt is more common in women; the current study was undertaken with an aim to understand clinical profile of female suicide attempters.

METHODOLOGY: This is a cross-sectional hospital based study. The study was carried out at the Vydehi Institute of Medical Sciences and Research Center, Bangalore which is a multispecialty tertiary-care teaching hospital. Department of Psychiatry of the Institute runs round-the-clock emergency 
services. Whenever a patient comes to hospital with intentional self-harm/suspected self-harm of any kind, the psychiatric referral team is consulted for detailed psychiatric evaluation. The details of the attempt was collected in a semistructured proforma and the cases were evaluated for the presence of psychiatric morbidity using M.I.N.I.-Plus.(8)

The intentionality was assessed using Beck Suicide Intention Scale (SIS).(9) The SIS is a 15 -item questionnaire designed to assess the severity of suicidal intention associated with an episode of self-harm. Each item scores 02 , giving a total score range of $0-30$. The questionnaire is divided into two sections: the first 8 items constitute the 'circumstances' section (Part 1) and are concerned with the objective circumstances of the act of self-harm; the remaining 7 items, the 'self-report' section (Part 2), are based on patients' own reconstruction of their feelings and thoughts at the time of the act.

To examine the relationship between suicidal intent and patient characteristics, total SIS scores were divided into two categories 'low' and 'high' by taking the median score.(10) For this study the cases referred for the suicide attempt during the period of January-June 2012 were included. During this period total cases referred were 103 and in this 57 cases were female suicide attempters. Informed consent was taken from the subjects. The study was approved by the institutional ethics committee.

RESULTS: More than half of the cases (56\%) were in the age group of $11-20$ yrs and $51 \%$ of the cases were married. More than three fourths of the patients were from urban area and belonged to the nuclear family. Majority of the cases belonged to Hindu religion $(82.5 \%)$, were employed $(41.5 \%)$ and were from middle socio-economic status (65\%) (Table- 1$)$. Consumption of chemical compounds in the form of selfpoisoning $(44 \%)$ and drug over dosage $(32 \%)$ were the common methods of attempt. In $79 \%$ of the subjects it was their first attempt and 53\% had high intentionality and in $70 \%$ of the cases the attempt was impulsive.

The common stressors associated with majority of the cases were marital discord (42\%) followed by interpersonal conflicts (38\%). About $96 \%$ of the cases had Psychiatric diagnosis, in that Adjustment disorder was present in $75 \%$ of the cases followed by depressive disorder in $16 \%$ (Table 2). Among the married females; self-poisoning (48\%) was the common method where as in unmarried females drug over dosage (48\%) was the common method.

Marital discord was the major stressor associated with the married females (83\%) and in unmarried females interpersonal conflict was the common stressor associated (Table-3). In adolescents self-poisoning (53\%) was the common method of attempt, intentionality was high (69\%) when compared to the adult attempters. Interpersonal conflict (Other than spouse) was the common stressor present in the adolescents (57\%); Adjustment disorder was the diagnosis in majority of adults and adolescents (Table -4).

DISCUSSION: Most of the patients in our study were in the age group of $11-20 y r s(56 \%)$. This period is considered as adolescent period where lot of major decisions of life has to be taken and is the most turbulent period of life. Especially in the females where the individual aspiration gets clashed with their families desires especially in the sphere of their marriage. Other studies also mention that suicidal attempt is more among young adults. $(4,5,11,12,13,14)$

In the current study $51 \%$ of the cases were married and we had almost equal number of cases who were unmarried $(47 \%)$ and divorced were (2\%). As in our study about $56 \%$ of the patients were in the age group of 11-20 yrs, in this age group as expected more of unmarried people were there. In many western studies. $(15,16,17)$ marriage has been found to be the protective factor but in some Indian studies the rate of suicide attempt is more in married people.(5)

Here in India marriage is a social obligation and is performed by the elders irrespective of the individuals preparedness for it. Marital partners in India are virtually strangers to each other (Due to the arrange marriage) and so are the families. Divorce in Indian society is socially frowned upon and suicide provides the only escape. Married females attempted suicide because of adjustment problems with husband and mother-in-law, forced marriage, and financial restraints. ${ }^{(18)}$

It is estimated there are worldwide more than 51 million adolescent girls aged 15-19 who are married and bearing the burden of domestic responsibility and the risks associated with early sexual activity, including pregnancy. In our study large percentages of the patients were from urban area $(77 \%)$. This can be explained as this is a tertiary hospital and is surrounded by the IT Industry, so most cases were from urban area when compared to the rural area. Seventy nine percent of the cases in this study belonged to the nuclear family.

This corroborates with other Indian studies.(11,13,14) Joint family system is decreasing as the urbanization is at an increasing trend. The more demanding nature of the nuclear families coupled with stress and strains, adds fuel to the fire. The support of the family members during the time of crisis which is a protective factor is reducing and the trend towards the nuclear family is increasing, so is the increase rate of suicide attempters in the nuclear families.

In our study, 23 (41.5\%) were employed, $23 \%$ were unemployed, $19 \%$ were house wives and $17.5 \%$ were students. Out of those who were employed 19 were married. Being employed gives a financial independence and should reduce the risk for the attempt but in our study they were not able to manage both the roles adequately and it is found that they had the more problem in the family sphere than in the occupational sphere.

The most common method of the attempt was by consuming chemical compounds (76\%) of which $44 \%$ by selfpoisoning and $32 \%$ by drug over dosage. This is in accordance with many Indian studies done on suicide. $(11,12,13,14,19)$ The poisons used were those usually used in the houses as insecticides or pesticides and drugs were those used by the family members like anti-hypertensives, oral hypoglycemics, antihistaminics and NSAIDS. Factors like feasibility, accessibility, credibility and rapidity of action could be behind the choice of method for the attempt. $79 \%$ of our patients were first time attempters and $21 \%$ had attempted more than one time.

All the patients who attempted more than one time had a psychiatric diagnosis and most common diagnosis was depressive disorder. Lethality was low in our subjects as most of our patients had used poisoning or drug over dosage as the method of attempt. Intentionality was high in 53\%. In adolescents the intentionality to end their life was more than the adults, as the adolescents are more impulsive and 
visualize immediate solution for the problem, so they would have used the attempt as a coping strategy to overcome the problem. In these subjects even though the intention to end life was high but due to insufficiency in knowledge regarding the lethal dose their life could be saved.

The act was planned in $30 \%$ of the cases and in $70 \%$ of the cases it was impulsive. Most of these cases had arguments with the family members or had received negative comments from the family members before the impulsive act. Only $12 \%$ had communicated about the suicidal ideas to the family members, but still no preventive measures were taken by the family members.

Out of 29 married cases, 24 had marital discord as the stress and this is recorded as the most common stress acting on the individual who attempted suicide. This was followed by interpersonal conflicts (Other than spouse) in 21 patients (38\%). In adolescent age group of 11-20 yrs, 10 were married and out of that 9 were having marital discord. In this young age they are not mature enough to understand the dynamics of the marital relationship and are not ready to take the responsibility of the spouse and the family.

In adolescent patients interpersonal conflicts was the stressor in $57 \%$ of the cases and in the unmarried females also this was the stressor associated with the attempt, the interpersonal conflicts were within the family members other than the spouse who included parents, siblings, and in-laws. Literature also supports that marital discord and interpersonal conflict with family members as stressors acting on the patients attempting for the suicide attempt. $(4,5,11,12,13,20,21)$

Adjustment disorder was the diagnosis in $75 \%$ of the patients followed by depression in $16 \%$ of the patients. Some Indian and Western literature also support our findings.(22,23) Adjustment disorder denotes a poor coping ability of susceptible individuals to adverse circumstances and they would adopt suicide attempt as a resort to solve the problems or to escape from the difficult situation. Although Adjustment disorder has been regarded as a "transitional or marginal diagnostic category", there are also reports of it being a common and serious condition among adolescents.

There were some limitations in this study. Study was for short duration of time. It was a hospital based study and cannot be considered as true representative of the general population. All the cases were not referred for the psychiatric consultation due to death or patient getting discharged. In some cases due to legal complication the family members and the patient would not disclose details adequately. Hence the findings should be interpreted in this background.

To conclude, in our study the subjects were young, below 20 yrs from urban area belonging to the nuclear family and most of the married women were working and were having marital discord as the most common stress followed by interpersonal conflicts. Poisoning was the common method of attempt and was impulsive in most of the cases with low lethality. Majority of the patients had psychiatric diagnosis which necessitates greater awareness of suicidal risk and early intervention as a preventive strategy.

Most of the subjects had Adjustment disorder as the diagnosis followed by depression. Suicide attempts are cry for help and are used by the subjects to communicate their needs and helplessness. Hence by promoting coping skills and by encouraging healthy interpersonal communication the risk for attempts can be reduced. Modifying the interpersonal relationship problems in the family might help in preventing the attempt. More and more help groups in the form of NGO's can make a significant contribution to the society.

LIMITATIONS: Current study is a cross-sectional hospital based study with small number and hence the results can't be generalized and future studies from community on larger populations is required to avoid bias and to increase the power of the study.

\section{REFERENCES:}

1. Suicide prevention-World Health organization. http//www.who.int/mentalhealth/prevention/suicide/ accessed on 12/10/2015.

2. National Crimes Records Bureau. Accidental Deaths and Suicides in India 2013. New Delhi: Ministry of Home Affairs, Government of India; 2014.

3. Vijaykumar L. Suicide and its prevention: The urgent need in India. Indian J Psychiatry 2007; 49:81-4.

4. Narang RL, Mishra BP, Nitesh M. Attempted suicide in Ludhiana. Indian J Psychiatry 2000; 42:83-7.

5. Nagendra Gouda M, Rao SM. Factors related to attempted suicide in devanagere.

Indian J Community Med 2008;33:15-8.

6. Joseph A, Abraham S, Muliyil JP, George K, Prasad J, Minz $\mathrm{S}$, et al. Evaluation of suicide rates in rural India using verbal autopsies, 1994-9.

BMJ 2003; 326:1121-2.

7. Gajalakshmi V, Peto R. Suicide rate in Tamil Nadu, south India: Verbal autopsy of 39,000 deaths in 1997-98. Int J Epidemiol 2007; 36:203-7.

8. Sheehan DV, Lecrubier Y, harnett-Sheehan K, Amorium $\mathrm{P}$, Janavs J, Weiller E, et al. The Mini International Neuropsychiatric Interview (M.I.N.I) The development and validation of a structured diagnostic psychiatric interview for DSM-IV and ICD-10.J.Clin Psychiatry 1994; 51:22-23.

9. Beck A., Schuyler D., Herman J. (1974) Development of suicidal intent scales. In The Prediction of Suicide (eds A.Beck, H. Resnik \& D. J. Lettieri), pp.45-56.Bowie, MD: Charles.

10. Harris L, Hawton K, Zahl D. Value of measuring suicidal intent in the assessment of people attending hospital following self-poisoning or self-injury; $\mathrm{Br} \quad \mathrm{J}$ Psychiatry;2005;186;60-6.

11. Das PP, Grover S, Avasthi A, Chakrabarti S, Malhotra S, Kumar S. Intentional self-harm seen in psychiatric referrals in a tertiary care hospital. Indian J Psychiatry 2008; 50:187-91.

12. Ramdurg S ,Goyal S, Goyal P, Sagar P, Sharan P. Sociodemographic profile, clinical Factors and mode of attempt in suicide attempters in consultation liason psychiatry in a tertiary care denter. Ind Psychiatry J 2011; 20; 11-6.

13. Rao KN, Kulkarni RR,Begum S. Comorbidity of psychiatric and personality disorders in first suicide attempters.Indian J Psychol Med 2013;35;75-9.

14. Ponnuduurai R, Jeyakar J, Saraswathy M. Attempted suicides in Madras; Indian J Psychiatry,1986;1; 59-62. 
15. Benda BB. Discriminators of Suicide Thoughts and Attempts among Homeless Veterans Who Abuse Substances. Suicide \& Life-Threatening Behavior 2003, 33(4), 430-42.

16. Mathy RM., Kerr SK., Lehmann BA. Mental Health Implications of Same-Sex Marriage: Influences of Sexual Orientation and Relationship Status in Canada and the United States. Journal of Psychology \& Human Sexuality 2003, 15(2-3), 117-41.

17. Kraut A., Walld R. Influence of lack of full-time employment on attempted suicide in Manitoba, Canada. Scandinavian Journal of Work, Environment \& Health.2003, 29(1), 15-21.

18. Joseph Raj MA, Kumaraiah V, Bhide AV. Social and clinical factors related to deliberate self-harm. NIMHANS J. 2000; 18(1\&2):3-18.

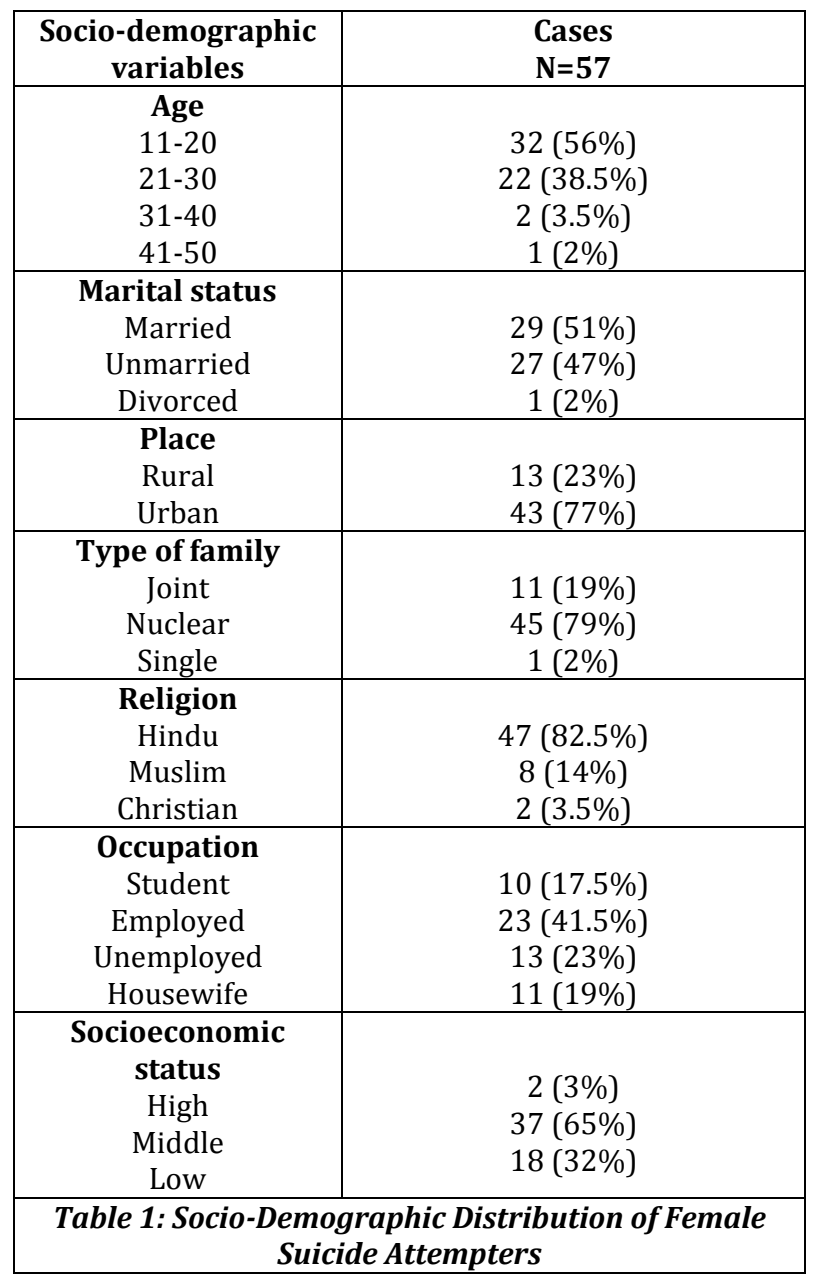

19. Latha KS, Bhat SM, D'Souza P. Suicide attempters in a general hospital unit in India: their socio-demographic and clinical profile-emphasis on cross-cultural aspects. Acta Psychiatr Scand 1996;94:26-30.

20. Sethi BB, Gupta SC, Singh H. Psychosocial factors and personality characteristics in cases of attempted suicide. Indian J Psychiatry 1978; 20-5.

21. Nordentoft M, Rubin P. Mental illness and social integration among suicide attempters in Copenhagen: comparison with the general population and a four year follow-up study of 100 patients. Acta Psychiatr Scand 1993; 88:278-85.

22. Baby, Haridas, Yesudas. Psychiatric diagnosis in attempted suicide, Calicut Medical Journal, 2006; 4(3); e-2.

23. Morgan HG, Burns-Cox CJ, Pocock H, Pottle S. Deliberate self-harm: clinical and socio-economic characteristics of 368 patients. $\mathrm{Br}$ J Psychiatr 1975127:564-74.

\begin{tabular}{|c|c|}
\hline Variables & Cases \\
$\mathbf{N = 5 7}$
\end{tabular}




\begin{tabular}{|c|c|c|c|}
\hline Nature & $\begin{array}{l}\text { Married } \\
\mathrm{N}=\mathbf{2 9}\end{array}$ & $\begin{array}{c}\text { Unmarried } \\
\mathrm{N}=\mathbf{2 7}\end{array}$ & $\begin{array}{c}\text { Statistical } \\
\text { analysis }\end{array}$ \\
\hline $\begin{array}{l}\text { Method } \\
\text { Hanging }\end{array}$ & $6(21 \%)$ & $2(7 \%)$ & $\mathrm{Z}=1.42$ \\
\hline $\begin{array}{c}\text { Poison } \\
\text { consumption }\end{array}$ & $14(48 \%)$ & $10(37 \%)$ & $\mathrm{Z}=0.84$ \\
\hline Burns & $2(7 \%))$ & $0(0 \%)$ & \\
\hline Drug overdose & $5(17 \%)$ & $13(48 \%)$ & $\mathrm{Z}=2.47^{*}$ \\
\hline Sharp objects & $2(7 \%)$ & $1(4 \%)$ & $\mathrm{Z}=0.53$ \\
\hline Drowning & $0(0)$ & $1(4 \%)$ & \\
\hline $\begin{array}{l}\text { Intentionality } \\
\text { High }\end{array}$ & $16(55 \%)$ & $14(52 \%)$ & $Z=0.53$ \\
\hline Low & $13(45 \%)$ & $13(48 \%)$ & $\mathrm{Z}=0.25$ \\
\hline $\begin{array}{l}\text { Lethality } \\
\text { High }\end{array}$ & $9(31 \%)$ & $7(26 \%)$ & $\mathrm{Z}=0.42$ \\
\hline Low & $20(69 \%)$ & $20(74 \%)$ & $\mathrm{Z}=0.42$ \\
\hline $\begin{array}{l}\text { Impulsivity } \\
\text { Planned }\end{array}$ & $12(41 \%)$ & $5(19 \%)$ & $\mathrm{Z}=1.86$ \\
\hline Impulsive & 17 (59\%) & $22(81 \%)$ & $\mathrm{Z}=1.85$ \\
\hline $\begin{array}{l}\text { No. of attempts } \\
\text { One attempt }\end{array}$ & $24(83 \%)$ & $20(74 \%)$ & $\mathrm{Z}=0.79$ \\
\hline Multiple attempt & $5(17 \%)$ & $7(26 \%)$ & $\mathrm{Z}=0.75$ \\
\hline $\begin{array}{c}\text { Stress } \\
\text { Financial stress }\end{array}$ & $1(3 \%)$ & $3(11 \%)$ & $\mathrm{Z}=1.11258$ \\
\hline Marital discord & $24(83 \%)$ & $0(0 \%)$ & $\mathrm{Z}=6.25^{*}$ \\
\hline $\begin{array}{l}\text { Interpersonal } \\
\text { conflicts } \\
\end{array}$ & $3(11 \%)$ & $18(67 \%)$ & $\mathrm{Z}=4.35 \%{ }^{*}$ \\
\hline Property dispute & $0(0 \%)$ & $4(15 \%)$ & $\mathrm{Z}=2.151^{*}$ \\
\hline $\begin{array}{l}\text { Occupational } \\
\text { problems }\end{array}$ & $1(3 \%)$ & $0(0 \%)$ & $Z=0.973$ \\
\hline $\begin{array}{l}\text { Scholastic } \\
\text { pressure }\end{array}$ & 0 & $1(3 \%)$ & $\mathrm{Z}=1.045$ \\
\hline Health related & 0 & $1(3 \%)$ & $\mathrm{Z}=1.045$ \\
\hline $\begin{array}{c}\text { Diagnosis } \\
\text { Adjustment } \\
\text { disorder } \\
\end{array}$ & 24 & $19(71 \%)$ & $\mathrm{Z}=0.77$ \\
\hline $\begin{array}{c}\text { Depressive } \\
\text { disorder }\end{array}$ & 4 & $6(23 \%)$ & $\mathrm{Z}=1.20$ \\
\hline Anxiety disorder & 1 & $1(3 \%)$ & $\mathrm{Z}=0.051$ \\
\hline Psychosis & 1 & 0 & $\mathrm{Z}=0.973$ \\
\hline No diagnosis & 1 & $1(3 \%)$ & $\mathrm{Z}=0.051$ \\
\hline \multicolumn{4}{|c|}{$\begin{array}{c}\text { Table 3: Comparison of Nature of Attempt in } \\
\text { Married and Unmarried Females }\end{array}$} \\
\hline
\end{tabular}

$*(\mathrm{p}<0.05)$

(Figures in parenthesis are percentages)

\begin{tabular}{|c|c|c|c|}
\hline Nature & $\begin{array}{c}\begin{array}{c}\text { Adolescent } \\
\mathrm{N}=32\end{array} \\
\end{array}$ & $\begin{array}{l}\text { Adult } \\
\mathrm{N}=25\end{array}$ & $\begin{array}{c}\text { Statistical } \\
\text { analysis }\end{array}$ \\
\hline Married & $10(31 \%)$ & $19(76 \%)$ & $\mathrm{Z}=3.35^{*}$ \\
\hline Unmarried & $22(69 \%)$ & $05(20 \%)$ & $Z=3.66^{*}$ \\
\hline Divorcee & $0(0 \%)$ & $1(4 \%)$ & $\mathrm{Z}=1.141$ \\
\hline $\begin{array}{l}\text { Method } \\
\text { Hanging } \\
\end{array}$ & $5(16 \%)$ & $03(12 \%)$ & $\mathrm{Z}=0.39$ \\
\hline $\begin{array}{c}\text { Poison } \\
\text { consumption }\end{array}$ & $17(53 \%)$ & $08((32 \%)$ & $Z=1.59$ \\
\hline Drug over dosage & $08(25 \%)$ & $10(40 \%)$ & $\mathrm{Z}=1.20$ \\
\hline $\begin{array}{c}\text { Use of Sharp } \\
\text { objects }\end{array}$ & $02(6 \%)$ & $01(4 \%)$ & $\mathrm{Z}=0.377$ \\
\hline Burns & 0 & $02(8 \%)$ & $\mathrm{Z}=1.621$ \\
\hline Drowning & 0 & $01(4 \%)$ & $\mathrm{Z}=1.141$ \\
\hline $\begin{array}{l}\text { Lethality } \\
\text { High }\end{array}$ & $08(25 \%)$ & 08(32\%) & $\mathrm{Z}=0.58$ \\
\hline Low & $24(75 \%)$ & $17(68 \%)$ & $\mathrm{Z}=0.58$ \\
\hline $\begin{array}{c}\text { Intentionality } \\
\text { High }\end{array}$ & $22(69 \%)$ & 08(32\%) & $\mathrm{Z}=2.75^{*}$ \\
\hline Low & $10(31 \%)$ & $17(68 \%)$ & $\mathrm{Z}=2.75^{*}$ \\
\hline $\begin{array}{c}\text { Impulsivity } \\
\text { Planned }\end{array}$ & $11(34 \%)$ & $06(24 \%)$ & $Z=0.849$ \\
\hline Impulsive & $21(66 \%)$ & $19(76 \%)$ & $\mathrm{Z}=0.849$ \\
\hline $\begin{array}{c}\text { Stress } \\
\text { Financial stress }\end{array}$ & $2(6 \%)$ & $3(12 \%)$ & $\mathrm{Z}=1.914$ \\
\hline Marital discord & $9(28 \%)$ & $15(60 \%)$ & $\mathrm{Z}=2.41^{*}$ \\
\hline $\begin{array}{c}\text { Interpersonal } \\
\text { conflicts }\end{array}$ & $18(57 \%)$ & $3(12 \%)$ & $\mathrm{Z}=3.43^{*}$ \\
\hline Property dispute & $1(3 \%)$ & $3(12 \%)$ & $\mathrm{Z}=1.301$ \\
\hline $\begin{array}{l}\text { Occupational } \\
\text { problems }\end{array}$ & $1(3 \%)$ & 0 & $\mathrm{Z}=0.891$ \\
\hline $\begin{array}{l}\text { Scholastic } \\
\text { pressure }\end{array}$ & $1(3 \%)$ & 0 & $\mathrm{Z}=0.891$ \\
\hline Health related & 0 & $1(4 \%)$ & $\mathrm{Z}=1.141$ \\
\hline $\begin{array}{c}\text { Diagnosis } \\
\text { Adjustment } \\
\text { disorder }\end{array}$ & $24(75 \%)$ & $19(76 \%)$ & $\mathrm{Z}=0.087$ \\
\hline $\begin{array}{l}\text { Depressive } \\
\text { disorder }\end{array}$ & $5(16 \%)$ & $4(16 \%)$ & $Z=0.038$ \\
\hline Anxiety disorder & $1(3 \%)$ & $1(4 \%)$ & $\mathrm{Z}=0.178$ \\
\hline Psychosis & $1(3 \%)$ & 0 & $\mathrm{Z}=0.891$ \\
\hline No diagnosis & $1(3 \%)$ & $1(4 \%)$ & $\mathrm{Z}=0.178$ \\
\hline
\end{tabular}

$*(\mathrm{p}<0.05)$

(Figures in parenthesis are percentages) 